Case Report

\title{
Diagnostic Challenge in a Patient with Severe Anion Gap Metabolic Acidosis
}

\author{
Eugene M. Tan, ${ }^{1}$ Ejaaz Kalimullah, ${ }^{2}$ M. Rizwan Sohail, ${ }^{3}$ and Kannan Ramar ${ }^{4}$ \\ ${ }^{1}$ Department of Internal Medicine, Mayo Clinic, 200 First Street SW, Rochester, MN 55905, USA \\ ${ }^{2}$ Department of Emergency Medicine, Loyola University Medical Center, 2160 S. 1st Avenue, Maywood, IL 60153, USA \\ ${ }^{3}$ Division of Infectious Diseases, Mayo Clinic, 200 First Street SW, Rochester, MN 55905, USA \\ ${ }^{4}$ Division of Pulmonary and Critical Care Medicine, Mayo Clinic, 200 First Street SW, Rochester, MN 55905, USA
}

Correspondence should be addressed to Eugene M. Tan; tan.eugene@mayo.edu

Received 31 March 2015; Revised 21 May 2015; Accepted 24 May 2015

Academic Editor: Caterina Mammina

Copyright (C) 2015 Eugene M. Tan et al. This is an open access article distributed under the Creative Commons Attribution License, which permits unrestricted use, distribution, and reproduction in any medium, provided the original work is properly cited.

The approach to the patient with acute renal failure and elevated anion and osmolal gap is difficult. Differential diagnoses include toxic alcohol ingestion, diabetic or starvation ketoacidosis, or 5-oxoproline acidosis. We present a 76-year-old female with type 2 diabetes mellitus, who was found at home in a confused state. Laboratory analysis revealed serum $\mathrm{pH} 6.84$, bicarbonate $5.8 \mathrm{mmol} / \mathrm{L}$, pCO2 $29 \mathrm{mmHg}$, anion gap $22.2 \mathrm{mmol} / \mathrm{L}$, osmolal gap $17.4 \mathrm{mOsm} / \mathrm{kg}$, elevated beta-hydroxybutyrate $(4.2 \mathrm{mmol} / \mathrm{L})$, random blood sugar $213 \mathrm{mg} / \mathrm{dL}$, creatinine $2.1 \mathrm{mg} / \mathrm{dL}$, and potassium $7.5 \mathrm{mmol} / \mathrm{L}$ with no electrocardiogram (EKG) changes. Fomepizole and hemodialysis were initiated for presumed ethylene glycol or methanol ingestion. Drug screens returned negative for ethylene glycol, alcohols, and acetaminophen, but there were elevated urine levels of acetone $(11 \mathrm{mg} / \mathrm{dL})$. The acetaminophen level was negative, and 5 -oxoproline was not analyzed. After 5 days in the intensive care unit (ICU), her mental status improved with supportive care. She was discharged to a nursing facility. Though a diagnosis was not established, our patient's presentation was likely due to starvation ketosis combined with chronic acetaminophen ingestion. Acetone ingestion is less likely. Overall, our case illustrates the importance of systematically approaching an elevated osmolal and anion gap metabolic acidosis.

\section{Introduction}

The presence of an osmolal gap in a patient with elevated anion gap metabolic acidosis typically alerts clinicians to toxic alcohol exposures, such as methanol, ethylene glycol, diethylene glycol, propylene glycol, or isopropanol. However, other disorders should be considered, such as diabetic or starvation ketoacidosis, acute kidney injury, chronic kidney disease, lactic acidosis, and salicylate intoxication, though not all of them create an osmolal gap [1]. However, to encompass an ever growing list of conditions resulting in elevated anion gap metabolic acidosis, particularly to account for 5-oxoproline (pyroglutamic acid) that is elevated in the setting of chronic acetaminophen ingestion, a new mnemonic was developed called GOLD MARK. This acronym stands for glycols, oxoproline (5-oxoproline also called pyroglutamic acid), L-lactate, D-lactate, methanol, aspirin, renal failure, and ketoacidosis [2]. We present a patient with an elevated anion gap metabolic acidosis and osmolal gap in the absence of toxic alcohol exposure, to illustrate the importance of using a systematic approach to arrive at the final diagnosis.

\section{Case Presentation}

A 76-year-old female with type 2 diabetes mellitus (hemoglobin Alc 6.3 on metformin therapy), overweight (BMI 28), and history of benzodiazepine and opiate use was found at home confused and lethargic, surrounded by water bottles containing pink fluid. A red-and-white pill with a \#5 inscribed (likely acetaminophen/oxycodone) was next to her, along with dark brown emesis stains. She was taking high doses of acetaminophen (sometimes exceeding 8 Extra Strength tabs daily) for back and leg pain for the past year. She used to take hydrocodone/acetaminophen but was no longer being prescribed this medication. She had been depressed 
TABLE 1: Admission laboratory values.

\begin{tabular}{|c|c|c|}
\hline Laboratory & Value & Reference \\
\hline Hemoglobin & $11.5 \mathrm{~g} / \mathrm{dL}$ & $12.0-15.5 \mathrm{~g} / \mathrm{dL}$ \\
\hline Hematocrit & $35.2 \%$ & $34.9-44.5 \%$ \\
\hline Leukocytes & $26.6 \times 10^{3}$ cells $/ \mathrm{uL}$ & $3.4-10.5 \times 10^{3}$ cells $/ \mathrm{uL}$ \\
\hline Leukocyte differential & $\begin{array}{c}85.6 \% \text { neutrophils, } 7.5 \% \text { lymphocytes, } 6.8 \% \text { monocytes, } \\
0 \% \text { eosinophils, and } 0.1 \% \text { basophils }\end{array}$ & $\begin{array}{c}41-77 \% \text { neutrophils, } 20-45 \% \text { lymphocytes, } 0-12 \% \\
\text { monocytes, } 0-6 \% \text { eosinophils, and } 0-2 \% \\
\text { basophils }\end{array}$ \\
\hline Platelets & $298 \times 10^{3}$ cells $/$ uL & $150-450 \times 10^{3}$ cells $/ \mathrm{uL}$ \\
\hline INR & 1.3 & $0.8-1.2$ \\
\hline Prothrombin time & 17.0 seconds & 9.5-13.8 seconds \\
\hline Sodium & $138 \mathrm{mM} / \mathrm{L}$ & $136-148 \mathrm{mM} / \mathrm{L}$ \\
\hline Potassium & $7.5 \mathrm{mM} / \mathrm{L}$ & $3.5-5.0 \mathrm{mM} / \mathrm{L}$ \\
\hline Creatinine & $2.1 \mathrm{mg} / \mathrm{dL}$ & $0.6-1.1 \mathrm{mg} / \mathrm{dL}$ \\
\hline Blood urea nitrogen & $52.6 \mathrm{mg} / \mathrm{dL}$ & $6.0-21.0 \mathrm{mg} / \mathrm{dL}$ \\
\hline Chloride & $111 \mathrm{mmol} / \mathrm{L}$ & $100-108 \mathrm{mmol} / \mathrm{L}$ \\
\hline Bicarbonate & $5.8 \mathrm{mmol} / \mathrm{L}$ & $21-32 \mathrm{mmol} / \mathrm{L}$ \\
\hline Calcium & $8.8 \mathrm{mg} / \mathrm{dL}$ & $8.4-10.4 \mathrm{mg} / \mathrm{dL}$ \\
\hline Total protein & $7.4 \mathrm{~g} / \mathrm{dL}$ & $6.3-8.2 \mathrm{~g} / \mathrm{dL}$ \\
\hline Magnesium & $2.3 \mathrm{mg} / \mathrm{dL}$ & $1.6-2.3 \mathrm{mg} / \mathrm{dL}$ \\
\hline Alkaline phosphatase & $83 \mathrm{IU} / \mathrm{L}$ & 55-142 IU/L \\
\hline AST & $41 \mathrm{IU} / \mathrm{L}$ & $15-46 \mathrm{IU} / \mathrm{L}$ \\
\hline ALT & $41 \mathrm{IU} / \mathrm{L}$ & $10-43 \mathrm{IU} / \mathrm{L}$ \\
\hline Total bilirubin & $<0.40 \mathrm{mg} / \mathrm{dL}$ & $0.10-1.00 \mathrm{mg} / \mathrm{dL}$ \\
\hline Blood and urine cultures & No growth & No growth \\
\hline
\end{tabular}

and was previously on sertraline but had self-discontinued the drug for unknown reasons. Although she was never formally diagnosed with dementia, her daughter mentioned she had difficulty taking care of herself and was not eating, drinking, and taking medications appropriately for several weeks at least. She became progressively somnolent and was admitted to the ICU.

On admission, venous blood gas revealed serum $\mathrm{pH} 6.84$, serum bicarbonate $5.8 \mathrm{mmol} / \mathrm{L}$, and anion gap $22.2 \mathrm{mmol} / \mathrm{L}$ $(\mathrm{Na}=138 \mathrm{mmol} / \mathrm{L}, \mathrm{Cl}=110 \mathrm{mmol} / \mathrm{L})$, consistent with an anion gap metabolic acidosis. Other laboratory values included BUN $52.6 \mathrm{mg} / \mathrm{dL}$, creatinine $=2.1 \mathrm{mg} / \mathrm{dL}$, elevated beta-hydroxybutyrate $(4.2 \mathrm{mmol} / \mathrm{L})$, normal lactate $1.5 \mathrm{mmol} / \mathrm{L}$, and random blood sugar $213 \mathrm{mg} / \mathrm{dL}$. See Table 1 for additional laboratory values. Serum osmolality was elevated at $324 \mathrm{mOsm} / \mathrm{kg}$. As her calculated osmolality was $306.6 \mathrm{mOsm} / \mathrm{kg}(\mathrm{Na}=138 \mathrm{mmol} / \mathrm{L}, \mathrm{BUN}=52.6 \mathrm{mg} / \mathrm{dL}$, and glucose $=213 \mathrm{mg} / \mathrm{dL}$ ), there was an osmolal gap of $17.4 \mathrm{mOsm} / \mathrm{kg}$. Her potassium was $7.5 \mathrm{mmol} / \mathrm{L}$, but an EKG showed no peaked $\mathrm{T}$ waves (Figure 1). However, she was given intravenous bicarbonate, insulin, glucose, calcium, and nebulized albuterol to treat the hyperkalemia. Given the elevated anion and osmolal gap and suspicion for ethylene glycol or methanol ingestion, 2 doses of fomepizole $(670 \mathrm{mg}$ IV Q12H) and 2 hemodialysis sessions were initiated while drug levels of these alcohols were still pending.

Serum and urine drug screens returned negative for ethylene glycol, methanol, ethanol, isopropanol, acetaminophen,

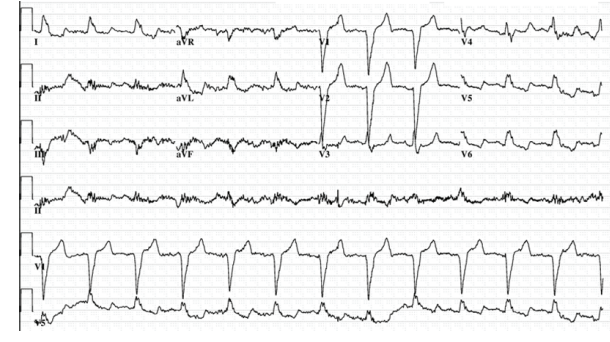

FIGURE 1: EKG showed prolonged QT, left bundle branch block, and left axis deviation but no $\mathrm{T}$ wave changes compared to a prior EKG.

and salicylates, but there were elevated levels of acetone $(11 \mathrm{mg} / \mathrm{dL})$ in the urine. Serum acetone was however not detectable. Her daughter later reported seeing a bottle of nail polish remover in her mother's house, though a direct ingestion history was not available. Due to the elevated betahydroxybutyrate and acetone levels, starvation ketosis was also entertained, and the patient was given thiamine along with intravenous glucose followed by enteral nutrition with close monitoring for refeeding syndrome. After a 5-day stay in the ICU, her mental status improved with supportive care. She was unable to clearly recount what occurred prior to her hospital admission, however. Creatinine returned to baseline of $0.8 \mathrm{mg} / \mathrm{dL}$. She was transferred to the general floor and discharged to a nursing facility. 


\section{Discussion}

Our case illustrates the diagnostic challenges in establishing an etiology for our patient's elevated anion gap metabolic acidosis and osmolal gap in the absence of alcohols such as methanol and ethylene glycol and in the presence of elevated beta-hydroxybutyrate and acetone levels. Despite the finding of high urine acetone concentrations, this may not necessarily mean that our patient ingested acetone as acetone may not typically produce laboratory findings of high anion gap and osmolal gap. However, acetone can possibly yield an elevated anion gap via ketosis or kidney injury with subsequent uremia, which our patient did have. The acetone metabolites, acetol and 1,2-propanediol, can possibly cause an increased osmolal gap as well [3].

In the literature, there are two case reports from Sweden in which patients admitted drinking alcohol but had only high concentrations of acetone in urine $(0.10 \mathrm{~g} / \mathrm{dL}$ and $0.052 \mathrm{~g} / \mathrm{dL}$ ). No ethanol or isopropanol was found. The investigators surmised that this was due to the longer elimination half-life of acetone (17-27 hours) versus isopropanol (1-3 hours). High concentrations of acetone in body fluids are found with ingestion of isopropanol because isopropanol is converted into acetone by oxidation with class I isoenzymes of hepatic alcohol dehydrogenase. Acetone is mostly excreted unchanged in the breath and urine, but some may be oxidized by cytochrome P450 enzymes via slow detoxification [4].

Abnormally high concentrations of acetone may also be found in the blood, breath, or urine of patients with diabetic or starvation ketoacidosis. When carbohydrate reserves are depleted, the body breaks down fat to produce ketone bodies such as beta-hydroxybutyrate, acetoacetate, and acetone. Acetone may be involved in the conversion of fat to carbohydrate during prolonged periods of fasting [4]. Our patient did have type 2 diabetes mellitus, and she had an elevated betahydroxybutyrate of $4.2 \mathrm{mmol} / \mathrm{L}$, but her random blood sugar was $213 \mathrm{mg} / \mathrm{dL}$, which did not meet the criteria for diabetic ketoacidosis. Her metformin use can cause lactic acidosis via blockade of gluconeogenesis, glycogenolysis, mitochondrial respiration, and oxidative phosphorylation, but her lactate was normal [5]. Metformin is unlikely to cause ketoacidosis, and no literature has been found. Hence, the elevated acetone and beta-hydroxybutyrate levels probably suggest starvation ketoacidosis, which was later confirmed by the patient and her daughter and based on her malnourished state.

Though less likely in our patient, we have to also be vigilant about other alcohol ingestions such as diethylene or propylene glycol as these alcohols may not be detected by laboratory testing. It is also worth noting that our patient had a history of chronic acetaminophen ingestion for pain, which is associated with reduced plasma glutathione levels, therapeutic or low acetaminophen levels, and elevation of 5-oxoproline levels in serum and urine. The exact mechanism for 5-oxoproline production is unknown, but the incidence of severe anion gap metabolic acidosis from 5oxoproline and chronic acetaminophen ingestion is higher if the patient has comorbidities such as malnourishment, pregnancy, vegetarian diet, sepsis, chronic renal insufficiency, or hepatic dysfunction. Diagnosis is confirmed by measuring urine 5-oxoproline, acetoacetate, 3-hydroxybutyrate, lactate, and 2-hydroxy acids [2]. The initial acetaminophen level in our patient was negative. Though our patient did not have a 5-oxoproline measurement, based on her history of chronic acetaminophen ingestion, decreased oral intake, and negative tests for alcohols, we speculate that her 5-oxoproline measurement might have been elevated.

In conclusion, we strongly suspect that our patient's abnormal laboratory values were likely to be explained by starvation ketosis in the setting of malnourishment and chronic acetaminophen ingestion. Though possible, it is less likely that our patient ingested acetone. Our case illustrates the importance of systematically approaching a diagnostic dilemma of a patient with elevated anion gap metabolic acidosis and an elevated osmolal gap, in the absence of toxic alcohols, to arrive at a diagnosis.

\section{Conflict of Interests}

The authors declare that there is no conflict of interests regarding the publication of this paper.

\section{References}

[1] J. A. Kraut and S. X. Xing, "Approach to the evaluation of a patient with an increased serum osmolal gap and high-aniongap metabolic acidosis," American Journal of Kidney Diseases, vol. 58, no. 3, pp. 480-484, 2011.

[2] J. L. Duewall, A. Z. Fenves, D. S. Richey, L. D. Tran, and M. Emmett, "5-oxoproline (pyroglutamic) acidosis associated with chronic acetaminophen use," Proceedings (Baylor University. Medical Center), vol. 23, no. 1, pp. 19-20, 2010.

[3] J. A. Kraut and I. Kurtz, "Toxic alcohol ingestions: clinical features, diagnosis, and management," Clinical Journal of the American Society of Nephrology, vol. 3, no. 1, pp. 208-225, 2008.

[4] A. W. Jones, "Elimination half-life of acetone in humans: case reports and review of the literature," Journal of Analytical Toxicology, vol. 24, no. 1, pp. 8-10, 2000.

[5] D. M. Dell'Aglio, L. J. Perino, Z. Kazzi, J. Abramson, M. D. Schwartz, and B. W. Morgan, "Acute metformin overdose: examining serum $\mathrm{pH}$, lactate level, and metformin concentrations in survivors versus nonsurvivors: a systematic review of the literature," Annals of Emergency Medicine, vol. 54, no. 6, pp. 818-823, 2009. 


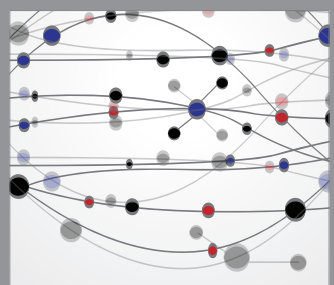

The Scientific World Journal
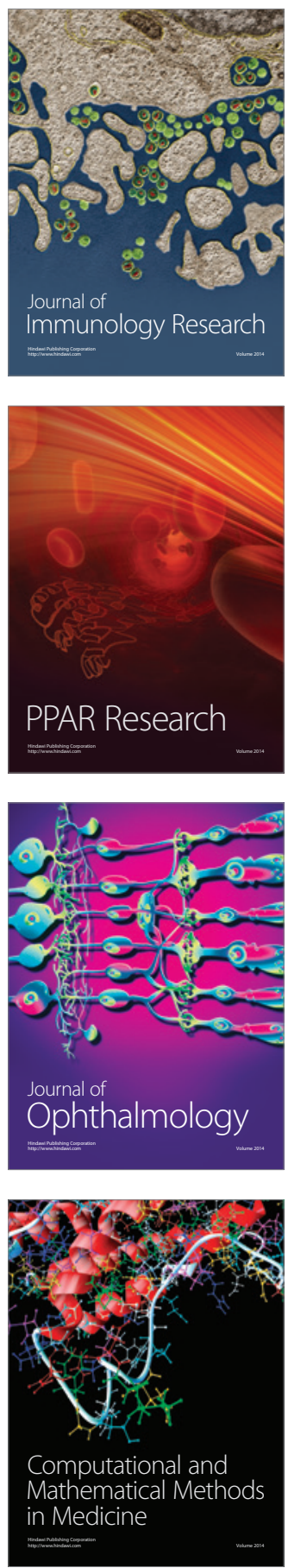

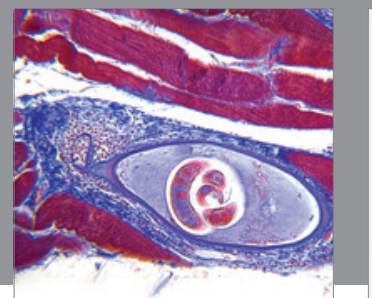

Gastroenterology

Research and Practice
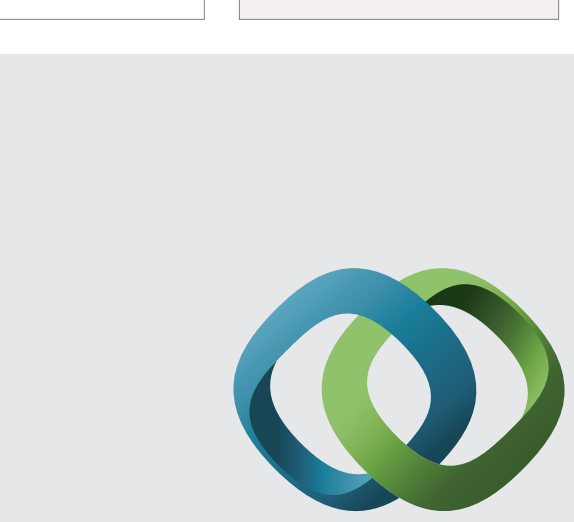

\section{Hindawi}

Submit your manuscripts at

http://www.hindawi.com
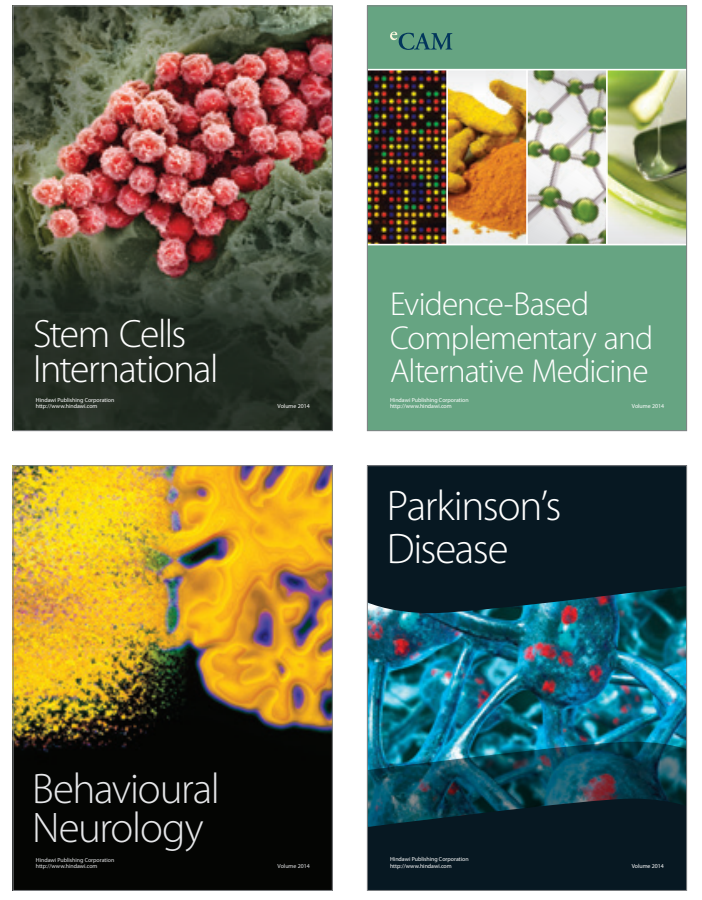
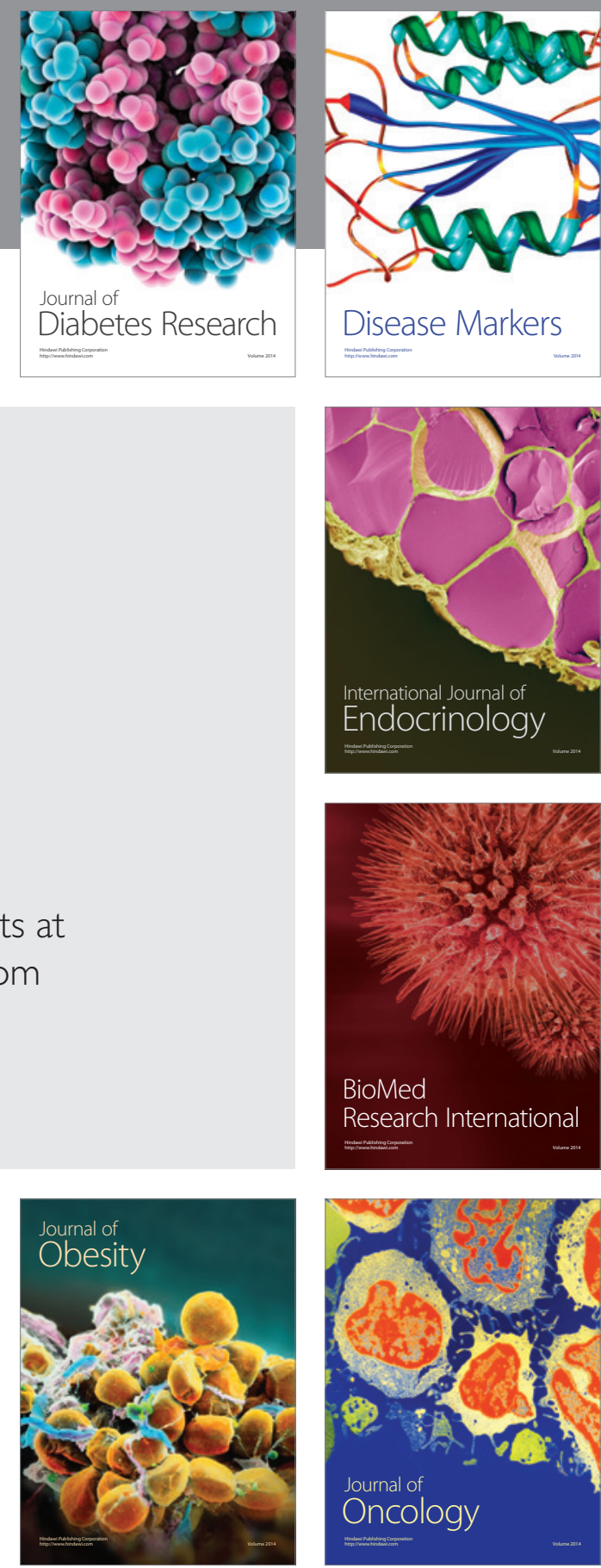

Disease Markers
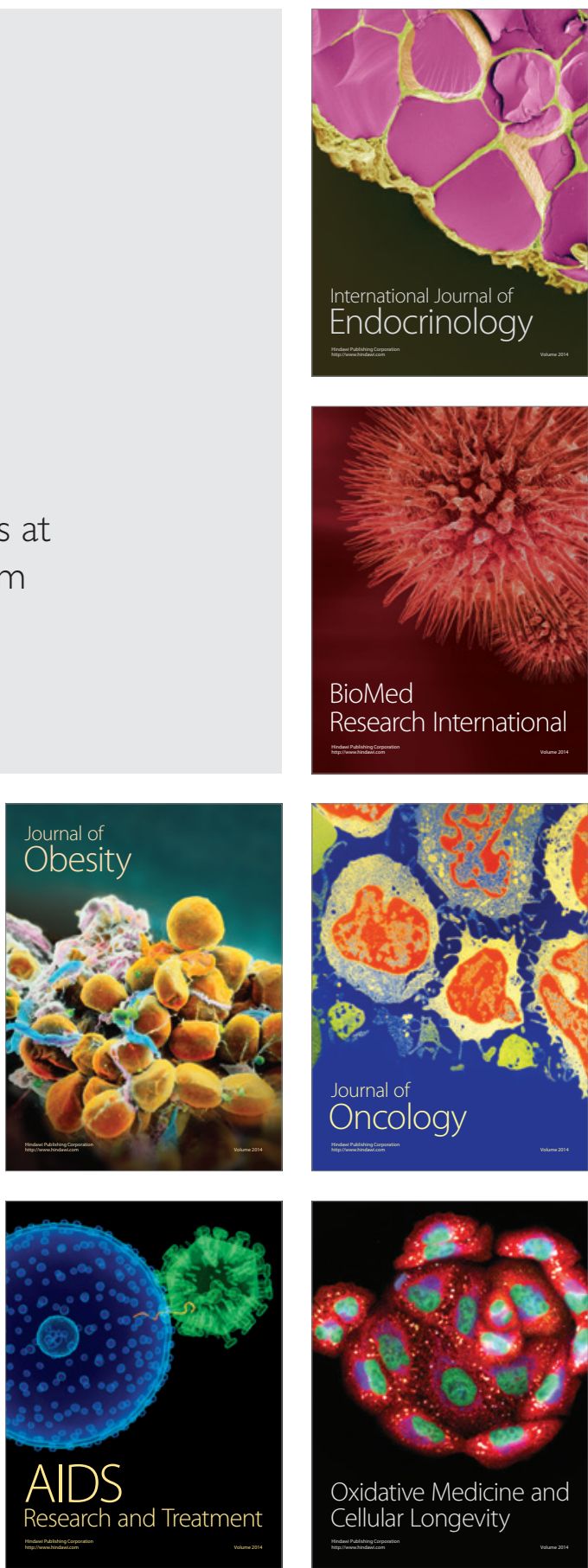